\title{
Quality of life of living with a transplanted liver: The issue of returning to normalcy
}

\author{
Bethli Wainwright ${ }^{1}$, Marilyn J Waring ${ }^{1}$, Shirley Julich², Polly Yeung² and Jenny K Green ${ }^{2}$
}

\begin{abstract}
INTRODUCTION: Advanced technology in medical and pharmacology has increased surgical survival rates for transplant recipients. Therefore, post-transplant care is critical and tightly connected with key focuses on the recipient's quality of life (QOL). Post-transplant QOL is multifaceted, encompassing morbidity and personal, social, familial and environmental support for recipients. Post-liver transplantation recovery extends well beyond returning home.

METHOD: Building on Wainwright's research (Wainwright, 2011a, 2011b; Wainwright, Jülich, Waring, Yeung, \& Green, 2016), herself a liver transplant recipient, this article reports transplant recipients' perceptions and experiences after the first three years and discusses how they reestablished function in everyday life as they adapted to their new normal to achieve QOL. The research employed interpretive description to interview transcripts and field-notes of 17 liver transplant recipients. Data were evaluated according to inductive thematic analysis. Eschewing the health-related QOL measure for its rigidity and lack of qualitative data, this research captured the lived experiences of liver transplant recipients unlike clinically focused studies.

FINDINGS: The results showed that, although transplantation can make positive changes in their lives, recipients continued to be influenced subtly by illness which can alter their reconceptualisation and re-definition of QOL and normalcy. The success of a liver transplant does not depend only on the physical care given; to the recipients as the spectre of future ill health and transplant failure continue to be perceived as a constant risks. Ongoing support from family, friends, and healthcare professionals are none-the-less fundamental in the posttransplantation journey.
\end{abstract}

KEYWORDS: social work and health care, quality-of-life, chronic illness, normalcy
${ }^{1}$ Auckland University of Technology, New Zeland

${ }^{2}$ Massey University, New Zealand
Liver transplantation is a relatively recent medical intervention available to clinically assessed, selected patients with acute or chronic liver failure, or small hepatocellular carcinoma (Gane et al., 2002). The development in this field is reflected in its associated body of literature in that it has been dominated by clinically focused research articles (Forsberg, Bäckman, \& Möller, 2000; Robertson, 1999). In the early days of liver transplantation, recovery meant simply going home (Lumby, 1997) and little was known about the quality of life (QOL) for recipients as they moved beyond recovery, returned to their families and communities and resumed their lives. There are various definitions of QOL depending on the associated paradigm (Walker \& Lowenstein, 2009), but the general concept of QOL includes dimensions of people's
AOTEAROA

NEW ZEALAND SOCIAL WORK 30(1), 7-19.

CORRESPONDENCE TO: Shirley Julich

S.J.Julich@massey.ac.nz 
lives ranging from their social connections to adequacy of income. In recent years, several dimensions of QOL have been discussed in the literature on transplant recipients, including physical health and employment (Dhooper \& Wilson, 1989; Simmons \& Abress, 1990), psychosocial wellbeing and life satisfaction (Paris et al., 1997).

While improvements in QOL in posttransplant recipients are evident and verified in quantitative research studies to provide objective physical parameters, if recipients' care is to be improved, it is important to note their perspectives on any pertinent aspects of QOL that cannot be statistically quantified (Sargent \& Wainwright, 2007). The emergence of research focussing healthrelated QOL continues to be underpinned by the clinical paradigm. This approach has been criticised because rigid methodological approaches can exclude phenomena that are difficult to define or measure (Åberg, Isoniemi, \& Höckerstedt, 2011; Dudley, Chaplin, Clifford, \& Mutimer, 2007). While a review of the quantitative literature on posttransplant indicated significant associations with QOL (Dew et al., 1997), understanding of patients' QOL experiences and their journey to regain normality is still lacking. The first author of this article, herself a liver transplantation recipient, found that clinically based QOL instruments, such as the Medical Outcomes Study 36-Item ShortForm Health Survey (SF-36) (Hill, Harries, \& Popay, 1993; Wainwright, 2011a), did not sufficiently address the characteristics of post-operative wellbeing that were significant to her. Other researchers (Blanch et al., 2004; Littlefield et al., 1996; Lumby, 1997) have noted that generic measures do not necessarily capture important transplantspecific domains based on the lived experience of liver transplantation recipients.

There is limited research on the journey of recipients as they return to the activities of daily life and reconnect with valued roles previously relinquished because of chronic illness (Åberg et al., 2011; Akazawa, Nishizono, Yamamoto, Teraguchi, \&
Hayashi, 2013; Scott \& Brown, 2012). Dew, Goycoolea, Switzer, and Allen (2000) found that most recipients, over time, experience an improvement in physical health QOL followed by cognitive and social role functioning. Similarly, van der Mei et al. (2007) studied social participation among kidney transplantation recipients investigating the actual time they spent on such activities as household tasks, social relationships, and community activities. Scott (2010) argued that "an important component of social functioning is the ability to fulfil a variety of life roles" (p. 517). People perform a variety of roles in their daily lives - how they relate to others, or their inability to do so, impacts on self-esteem and thus QOL.

McKenna, Liddle, Brown, Lee, and Gustafsson (2009) investigated role participation and life satisfaction by comparing older people with and without experience of stroke with the use of two measures, the Role Checklist (Oakley, Kielhofner, Barris, \& Reichler, 1986) and the Life Satisfaction Index-Z (McKenna et al., 2009). For both groups, the most valued roles were family member, friend, and home maintainer. In her study of liver transplantation recipients some five years after transplant surgery, Scott (2010) found that the most valued roles included family member, home maintainer, friend and the additional role of worker. Given that almost $75 \%$ of Scott's sample of participants was under the age of 65 years, it is not surprising that the valued worker role was included. Home maintainer was also valued more highly than friend by liver transplantation recipients than the older cohort of stroke victims in McKenna et al. (2009) which may reflect the age-span between the two cohorts and more dependent children or partners in Scott's sample. Scott's (2010) and McKenna et al.'s (2009) studies both indicated that those who participated in a higher number of valued roles reported higher levels of QOL. However, some people returned home and struggled with physical and psychological recovery (Scott \& Brown, 2012), which impacted on their ability to resume valued roles. Before these can be resumed, the 
liver transplant recipient needs to recover from surgery and come to terms with the limitations this might entail. They need to regain their independence before they can reconnect with previously relinquished valued roles. This requires support in all domains of their lives from family members to community agencies and governmentfunded organisations.

With the rising success of liver transplantation compared to non-surgical treatment, gaining patients' perceptions of QOL post-transplant and how these perceptions change over time is essential to describe the uniqueness and breadth of transplant recipients' experiences with complex chronic care management that is not normally accessible through quantitative research (Tong, Chapman, Israni, Gordon, \& Craig, 2013). Research inclusive of recipients' voice is rare across the transplantation body of knowledge (Akazawa et al., 2013), and is most commonly located in memoir or biographical writings (Casey, 1996; Hagman \& Gold, 2001; Maier \& Maier, 1991). A recipient-driven approach to researching the lived experience of liver transplantation is absent in the Aotearoa New Zealand context. To address this deficit, between 2008 and 2010 Wainwright (2011a, 2011b), the first author of this study, completed such research. Wainwright passed away on December 2010 and her research has been continued and supported by the remaining authors (Wainwright et al., 2016) to explore how liver transplant recipients dealt with the first phase of post-transplant recovery in returning to their own homes. Results from the previous study indicated that the early stage of post-transplantation requires healthcare professionals to facilitate effective clinical pathways that include timely patient education from pre-admission through to discharge into the community.

Building on the research published in 2016 (Wainwright et al., 2016), it is clear that postliver-transplantation recovery extends well beyond returning home. Existing research indicates that, although transplant recipients are typically discharged from hospital three to five weeks post-surgery and undergo intensive follow-up treatment in outpatient clinics for four to six months, support of patients through the post-transplant process is complex and multifaceted (Graarup, Mogensen, Missel, \& Berg, 2017). It often takes years for patients, families, and relatives to fully adjust to their new lives and some research has described the first post-surgery phase as a period of naiveté as recipients tend to feel immune to transplant-related complications (De Vito Dabbs et al., 2004). To achieve successful recovery, patients require regular information and support with posttransplant guidelines, ongoing support from healthcare professionals as well as families, employers, and society in general (Ivarsson, Ekmehag, \& Sjöberg, 2012). The current article extends Wainwright's previous work (Wainwright, 2011a, 2011b; Wainwright et al., 2016) which explored liver transplant recipients' perceptions and experiences after the first three years, and discusses how they re-establish function in everyday life as they adapt to their new normal to achieve QOL. It is important to note that the current research topic was selected because of the first author's own lived experience of liver transplantation (Wainwright, 2011a).

\section{Methods}

\section{Study design}

This qualitative study used Thorne's (2008) interpretive description methodology, widely used in the applied health disciplines. Interpretive description adopts a constructivist and naturalistic research orientation and was chosen for its ability to inductively describe the sensitive subject of liver transplant recipients' experience of care and what matters most in their QOL postrecovery through an interpretive lens. As the experience of human health and illness is influenced by multiple phenomena, health and social welfare professionals such as social workers can gain a deeper understanding on how people experience their health and illness and what they can do to make a difference (Thorne, Kirkham, \& MacDonald-Emes, 1997). This method can reveal common subjective 
associations, relationships and patterns found under shared conditions to generate an interpretive explanation while exploring variations among individuals (Hunt, 2009).

Ethics approval was granted by the Auckland University of Technology Human Ethics Committee (AUTEC 08/81) in June 2008. Informed consent was obtained from all study participants.

\section{Sample/participants}

The first author undertook all participants' recruitment and conducted all the interviews. The recruitment and selection of liver transplant recipients have been reported elsewhere (Wainwright et al., 2016). In brief, participants were sourced through the New Zealand Liver Transplant Unit (NZLTU) where the staff applied three main eligibility criteria to the database of recipients. They were: (1) recipients who had received a liver from a deceased donor between 1998 and 2005; (2) English-speaking adults; and (3) residents in New Zealand. The rationale for recruiting recipients who received their first liver transplant between 1998 and 2005 was, prior to 1998, New Zealanders had to travel overseas for liver transplants or died without transplant. The end-point of 2005 provided recipients with distance from the transplant to enable reflection without the influence of the initial mix of euphoria and depression, a phenomenon documented in the literature (De Vito Dabbs et al., 2004) and known to the first author from her own transplant experience. All participants in the current study had at least three years' post-transplant experience at the time of interview.

A total of 182 potential participants were identified for recruitment. Candidates for interview were initially selected by NZLTU staff who mailed information packs including a consent form to 20 of this group, which first generated seven responses - a $35 \%$ response rate. So that a $10 \%$ sample of the total eligible number could be interviewed, direct contact with eligible participants by the NZLTU resulted in an additional four participants, and a further six were found through the first author's networks of fellow patients. The final group of 17 who were successfully interviewed face-to-face were located across New Zealand.

Among the 17 recipients who participated in the interviews, nine were men and eight were women. Eleven participants described their ethnicity as New Zealand European/ Pākehā, followed by four Māori (Indigenous people in New Zealand), and two identified as other ethnicities. Five participants lived in the South Island of Aotearoa New Zealand. Twelve reported they lived in the North Island, with seven of them living in Auckland (the most populous urban area in New Zealand). Half of the participants reported being in the 20-50 age group, while the other half was older. This group reflected the ratios of liver transplant recipients in relation to gender, ethnicity, and geographic location in the transplant database as reported by the hepatologist at NZLTU (Wainwright, 2011a).

\section{Data collection}

Data were collected between 2008 and 2010. On receipt of signed consent forms from eligible recipients, arrangements were made by the first author to interview participants face-to-face at a convenient time and place. All interviews were recorded digitally and transcribed verbatim. The interviews usually lasted between 45 minutes and three hours. Aside from being asked to articulate their pre-transplant experiences (these stories set the scene for a discussion of their posttransplant experiences), participants were also encouraged to raise issues relating to wellbeing and QOL. To achieve this, neutral, nondirective probes were used as appropriate.

\section{Data analysis}

All transcripts were first compared with the audio-recordings for accuracy. Inductive thematic analysis was conducted and maintained in a holistic, contextualised perspective to view the data by using broad questions, for example, "why is this here?"; "what does it mean?" (Thorne, 2008). Constant 
comparative analysis and ongoing engagement with the data were used to confirm and explore conceptualisation. The transcripts were read and summarised independently by the first two authors, focusing on inductive rather than deductive analysis. These were then discussed with the third author to achieve investigator triangulation (Denzin, 1978; Thurmond, 2001) to reach points of convergence while acknowledging different interpretations and perspectives. The first author used field-notes and audio-recordings to ensure concepts derived from the data were identified and developed throughout the research process. NVivo version 8 software (QSR International Pty Ltd. 2008) was used to store, code and organise all interview data. Text fragments were coded and after comparison between the first two authors, the codes were renamed and categorised into a list of emergent themes. To maintain a rigorous analysis process, analysis of the data was only deemed complete when there was consensus within the research team regarding major themes.

\section{Results}

The two emergent themes related to QOL post-surgery on the resumption of valued roles and the description that was common to all participants in the current study as they described this period of their lives: shifting priorities and reclaiming independence and normalcy. To enrich the experience expressed by the participating liver transplant recipients on their QOL post-recovery, direct (anonymised) quotes have been used. From here, we refer to those who participated in this research as recipients or transplant recipients.

\section{Shifting priorities}

In her first publication, the first author (Wainwright, 2011b) reported that transplant recipients had significant changes in outlook and priorities. Although some changes to priorities were imposed, for example, changes in diet, lifestyle choices and the like, it appeared that liver transplantation had a catalysing effect on female recipients. They tended to make more changes in their lives post-transplant than recipient males. The joy of these changes and being able to re-engage in everyday tasks that are a feature of healthy people's daily lives seemed related to having suffered physical limitations pre-surgery. One female recipient commented on changing priorities:

My priorities have changed a lot ... when I realised that I would have been dead without the transplant ... I've just let things slide that would have really upset me in the past, I sort of feel it's just better to let them go and be happy, and just be a bit more relaxed about it all. And that life doesn't have to be a huge struggle, trying to do this and trying to do that. That maybe it's alright just to smell the flowers...

Irritations became less important. Wainwright (2011a) reflected that things such as rush hour traffic in Auckland did not bother her anymore, she appreciated being well enough to drive in it. Another female recipient commented on focusing on big dreams, not small issues, "It's given me a completely different outlook on life, ... don't sweat the small stuff ... if you want to do something, do it ... it's possible." Another noted that her awareness of, and empathy for, people in need grew, "I've just got more tolerance and more patience ... more understanding ... more empathy. I'm a lot more interested ... I gravitate towards people that may have issues."

The anniversary of the surgery is highly significant for recipients. It is a second birthday, a second chance at life, and it was likened to a birth, an opportunity to begin life again. Indeed, almost all recipients commemorate this date and on special anniversaries (five and 10 years), some send cards to the NZLTU. ${ }^{1}$

For the following two male recipients, this event had different importance. For the first, it was likened to a blip in life:

1 Personal communication May 13, 2016 with the NZLTU Nurse Practitioner. 
So that's why I say to people, if you're told you need an op., a major operation ... and it's going to make you better - take it. But keep your mind active, keep your mind on the fact that ... it's just a little blip while you're in, back to what you were doing before!

The other viewed it as an adventure to be embraced, "I was on an adventure, is the way that I've always felt about it ... the whole thing's been an adventure, and I've always felt very positively about it. Never worried about the outcome." All recipients acknowledged guilt at feeling relieved to be receiving the gift of life, while at the same time another family was grieving the loss of a loved one. This was particularly poignant when also considered from a cultural perspective.

I haven't gotten over that feeling of guilt ... Do I deserve this? Do I actually deserve to live, because somebody else had died, or to receive somebody else's liver? But ... also because I'd grown up in a culture where stories are told about evil spirits, and people coming back after death, and ghosts ... I was also really, really scared, that these things might happen.

While shifting priorities may imply recipients experiencing gratefulness for having been given the chance to have a better life, this was accompanied by concerns about rejection, feelings of guilt and disillusion about the new life and possibilities. They also noted the help they received from other recipients, the need to feel in control of minor things, to focus on life minute by minute and their dependency on others.

\section{Reclaiming independence and normalcy}

All recipients were dependent on family members or close friends for support in most facets of their lives. One recipient described this lack of independence as profound. She said she felt she had no control over her life or her destiny, that she was dependent on other people for everything. Family responsibilities were handed over to other people; control over, property, and finances was in the hands of others. Another recipient appeared to welcome dependence and less responsibility. For her, detachment from life appeared to be a coping mechanism and that regaining independence was a conscious effort.

All transplant recipients spoke about the support and assistance family members continued to provide when they returned home. They acknowledged and described the significant impacts on their families, both nuclear and extended. Recipients were torn between accepting support and establishing independence. Elderly parents had their own health challenges and some recipients indicated that they felt guilty asking their parents for help and support. As Rachael said, by wanting to be "thoughtlessly independent" it appeared her parents had felt excluded and that she had unwittingly hurt them by not asking them to accompany her to appointments.

Ruth said that as soon as her husband and mother-in-law saw her doing small chores around the house, they told her to go and sit down and do nothing. Dennis said that his wife would not leave him alone for his first two or three weeks at home. Elizabeth noted it was all very well having the attention, but it made her feel sorrier for herself. She said, "Why are they all fussing about me? You know, I am fine, I'll be fine, maybe I am not fine?" She went on to say that this attention created some conflict between her mother and her partner that she felt she had to manage. Both wanted the responsibility of looking after her. While all recipients appreciated support and were very grateful, they were also anxious to resume normal lives.

Transplant recipients spoke of cooking as a normal activity indicating that they were becoming more independent. Annette said, "My first major breakthrough was cooking a very light meal." She was so elated she called friends and told them. She said it was "utterly major." Walter, living outside of 
Auckland, said he started cooking "fairly soon" after leaving hospital. He said, "I went across to the butcher ... and got the [meal] cooking." Tom, also, commented on cooking a meal as regaining his independence. He said that once he had done that, his auntie said they can leave him alone now, and they did. Ruth said that for a long time she felt as though she did not belong. She felt unable to discuss this with her husband because he was exhausted working full-time and looking after the children. She commented that, if she was unable to do anything, what was the point of her being there? This feeling changed once she started cooking for her family. She said that when she could do things for her family again, she felt as though she belonged. An activity that many take for granted took on heightened significance in this journey towards independence.

Meanwhile, the ability to begin driving provided an additional sense of accomplishment and independence. Developing the confidence to drive takes time; in the early days following liver transplantation, recipients were driven by others. Some were worried about protecting the scar from the seat belt, for others wound protection was reliant on the awareness and skills of people driving them. Beth noted that initially, she used a pillow between the scar and the seat belt. Tom said that he felt his aunt was driving too fast. He had no perception of speed and was afraid that she might hit something and he would move forward and damage the operation site. He was so concerned he opted to use public transplant to gain some sense of independence.

Liver transplantation recipients might have been nervous at being driven, but they were keen to get back driving themselves to regain elements of control. Karen explained she was initially really scared of driving and worried about it. She said, "I was just too weak to turn the steering wheel ... It took me so long to be confident ... in the car." She said it was a big thing for her "getting back to driving and going back home." Regaining normalcy also means shifting people's expectations.
Helen talked about people at work who were over-protective:

I got back to full-time [work] and they found it hard to give me, you know, like, I needed more from them, sort of work wise ... one set of people were always getting the extra jobs that would advance their careers and stuff like that ... I actually talked to my manager about it and she said: "Oh well, you know, it's hard for us to realise that you're well now." You know? And ... “Oh we've probably been treating you a little bit different because you've been sick." And I said to her: "Well, I'm not sick anymore. I'm normal. I'm quite healthy." And it took them a little while to realise that.

Resuming previously held roles and responsibilities can be viewed as a spectrum with wide variations between transplant recipients. At one end of the spectrum, the role in the family was still open and recipients were expected to return and perform. At the other end recipients felt they had to fight their way back to retrieve their roles. This aspect of role changing and dynamics have been documented by $\mathrm{Xu}$ et al. (2012), who reported both positive and negative emotions in recipients and their families on carrying out social and family activities. This is exemplified by Charlie who said, "I'm very grateful to my [spouse], my [child], and my sister-in-law, and the two kids, well. When I went home, Gawd they were getting all over me like a blue-ass fly, you know? And I hate that." Similarly, Ruth commented:

...[spouse] come home: "What are you doing?" "I'm just sweeping a little bit here." "No, don't do that, go inside and sit down. Don't do anything." It was a sense when I felt that I could do things for us as a family again, I felt I belonged.

\section{Discussion}

This study explores liver transplantation as a lifesaving intervention from the perspective 
of Aotearoa New Zealand adult recipients and has implications for future research and practice of healthcare professionals such as social workers. Waiting for a liver transplant can be socially isolating. Much of the rhetoric focuses on liver disease, transplantation, and other health, or illness, related topics. The loss of independence is profound and permeates all aspects of recipients' lives. All transplant recipients in the study were impressed by the level of support and assistance they received from those helping them, particularly family members. This finding is consistent with a study on bone marrow transplant patients (Molassiotis, Van Den Akker, \& Boughton, 1997) that social support networks consisting of close and extended family members are essential to help with post-transplant patients' journeys. Regaining independence is not only an important QOL indicator but also it is an important recovery indicator. Notably, regaining independence enables liver transplantation recipients to resume previously relinquished valued roles, such as driving, and incorporate the organ as part of themselves. The transition from hospital-based to community-based services, for the most part, seemed to work well for recipients. Their responses suggested that health support for their specific needs was close and accessible. Notably, their comments highlighted the importance of individualised support assessments. While it is both crucial and appreciated, support means different things to different people. For all recipients fitness was an issue: either they wanted to regain their previous levels of fitness or be sufficiently fit so that they could move up and down stairs comfortably and resume some roles in the home that they deemed important. Research has identified the importance of social support during the recovery journey and adaptation to restore normal everyday living (Forsberg, Cavallini, Fridh, \& Lennerling, 2016). Recipients in the current study tended to use positive refocusing strategies and reappraisal to adapt to changed circumstances, similar to Grady et al.'s (2013) study of people who had received an organ transplant. Such coping and adaption mechanisms may mirror Zare et al.'s (2015) study that transplant recipients did not try to make an upward comparison of themselves with their healthy counterparts which can lead to self-doubt and loss of confidence; hence the focus on gaining normalcy and control.

While the recipients' accounts here demonstrated resilience and positivity, the possibility to live as normal a life as possible can be constrained by the transplantation trajectory. Sanderson and colleagues (2011) described two common types of normality: reset and disrupted normality. Neither involved a return to a normal level of being illness-free. Living with a transplanted organ has forced recipients to reconceptualise values or definition of health and QOL. Research has indicated that it may be an oversimplification for transplant recipients to understand health as an absence of symptoms, or being disease free and being able to function normally (Fagerlind, Ring, Brulde, Feltelius, \& Lindblad, 2010). Reclaiming normalcy may mean helping recipients to re-adjust to life (e.g., increasing tolerance of pain, fatigue, and disability) and redefining self (e.g., role and identity challenges) and health (e.g., the meaning of wellness) to reflect their own experiences.

All recipients were grateful for the transplant and commented on their determination to make it work; however, they also expressed concerns regarding uncertainty and the fear of rejection of the transplanted liver. This is consistent with Mantulak and Nicholas (2016) results of the existential experience of time and transplant vulnerability. Uncertainty during the post-transplant period can be related to the amount of time that has passed since transplant (Martin, Stone, Scott, \& Brashers, 2009). Mantulak and Nicholas (2016) argued that the passing of "time since transplant" (p. 590) is an important element but not necessarily considered as a sign of success. Meanwhile, existing research reports emotions such as gratefulness after transplantations (Neukom, Corti, Boothe, Boehler, \& Goetzmann, 2012). 
Yet, Schipper et al. (2014) have further illustrated that those high expectations of post-transplant may force recipients to change gratefulness into guilt because they are not allowed to be disappointed. Despite the facts of normalcy and expressions of desirable goals for a new life, half of the transplant recipients in the current study expressed difficulties in adhering to the requirements of life post-transplant. The importance of adherence to the requirements of post-transplant life is well documented (Seiler et al., 2016) but remains a huge challenge. We observed from the recipients' narratives that they expressed a deep fear of rejection of their new liver and a sense of uncertainty about their future even years post-transplant. Research has argued that, despite their good intentions, the influence of healthcare professionals may have instilled this fear and uncertainty because they emphasised compliance that can lead to distress and anxiety in recipients as they may feel personal responsibility for the success or failure of their new organ (Flynn, Daiches, Malpus, Yonan, \& Sanchez, 2013). Regardless of recipients' best efforts to take their medications consistently, attend regular check-ups and follow the instructions of healthcare professionals carefully, they will always face a unique transition from living with liver failure to living with a new liver and some levels of medical uncertainty such as medical regimens, organ rejection or recurrence of liver disease. This paradigm shift may be associated with new or worsening physiological and psychological symptoms over time, as recipients face mastery of a complex medication and surveillance regime, and changing expectations of family and friends (Doering et al., 2017). Therefore, it to be expected that they are constantly mindful of their new, transplanted organ. Existing studies indicate that, for a patient who is newly transplanted, life was usually described with a sense of hope, freedom, rebirth, and optimism (Graarup et al., 2017; Rosenberger, Dew, DiMartini, DeVito Dabbs, \& Yusen, 2012). Nonetheless, this study further highlights that the road to recovery,
QOL, and normalcy among liver transplant recipients who continue to survive is not straight forward.

\section{Implications for practice}

In both the Aotearoa New Zealand and international contexts, social workers are involved with transplant patients throughout the transplant and donation process, including short- and long-term follow-up. They are well positioned to assist transplantation recipients to gain access to government-funded assistance. It is likely that, on home discharge, transplantation recipients do not have the same access to a hospital-based social worker as they might have had in the time leading up to the transplant and while they were hospitalised. Returning home and moving beyond the initial recovery phase could be a vulnerable time for transplant recipients, as they move from hospital- to community-based services. Current research highlights that transplant recipients have high informational needs that are not restricted to medical issues at various time points post-transplantation (Ko, Lee, \& Muehrer, 2016; Ryu, Kim, \& Kang, 2003). With organ transplantation providing a positive clinical outcome and heightened life expectancy, regaining normalcy is also concerned with the recipient's QOL (Monroe \& Raiz, 2005).

Close family members gave willingly of their time, and from the recipients' responses they could be in competition with each other for the role of primary caregiver. Notably, too much support could undermine recipients' confidence in their capabilities. Attempts to regain independence over some areas of their lives were interpreted differently by caregivers and this can be construed as exclusion. Although recipients were appreciative of the support and assistance provided by caregivers, it created another stressful dynamic to the complexity of recovery that perhaps was not anticipated. Indeed, Scott (2010) noted that household roles which were taken on by others during the transplant recipient's treatment and recovery may not be relinquished willingly when the recipient has recovered. 
Zilberfein, Hutson, Snyder, and Epstein (2002) reported that social workers can provide family counselling for issues such as being a caregiver, marriage dynamics, and balancing employment role reversal changes in the family, particularly when the breadwinner can no longer support the family. They noted that recipients and their families may gain a new sense of life. However, the euphoria of posttransplant can dissipate once the reality of the side-effects of life-long medications and transplant rejection becomes apparent. Both recipients and their families will need support to deal with any such ramifications. Given the rapport and connection already established between recipients, families and the social worker pre-transplant, it would be beneficial to have the same social workers assisting them in the post-transplant journey. This study has reflected a greater need for post-transplant support service provision for both recipients and their families. Social workers in health care have the skills to go beyond medical conditions to engage with the needs of transplant recipients and their families through thorough assessments from a biopsychosocial perspective to ensure best practices. This underscores the value of a continuity of care model of practice to manage a transition process that supports transplantation recipients to resume a greater number of valued roles.

While the notion of normality achieved can vary for different conditions among recipients, the journey to establish and reestablish a new form of normalcy is a very personal construct, shaped by age, gender and a range of other contextual factors (Boaz \& Morgan, 2014). Social workers have the skills that involve both the patient and their social system whereas other professionals may look for more specific outcomes such as recovery from a medical condition or improvement in a particular function. For example, Siminoff and Chillag (1999) argued that recipients often experience intense and undue stress through many healthcare professionals emphasising the gift of life metaphor to influence patient behaviours.
Replacing failing livers with functioning onesmust be considered much more complex than a bio medical and technical life-saving procedure. The social worker's ability and critical knowledge on focusing the rights of the patients rather than just their needs can contribute further in transplant recipientcaregiver relationships by emphasising more on transplant-specific self-care and important areas that enhance QOL.

\section{Limitations}

Some limitations need to be considered when interpreting the findings. The current study had a small sample size; hence, the results are not generalisable to all liver transplant recipients' experiences. However, the first author with her own lived experience offers insider insight that helps triangulate the data from the transplant recipients, particularly to examine key issues that have not been adequately addressed by the support and understanding of transplantation recovery. This research conducted by Wainwright between 2008 and 2010 was the first of its kind in New Zealand and has sought to provide a fuller perspective of the lived experience of transplant recipients as they move beyond recovery and return to a new normal. Although the study was at least seven years old, to our knowledge this remains the first Aotearoa New Zealand based study on liver transplant experience conducted by a recipient that was recipientfocused as opposed to clinically focused.

\section{Conclusion}

Quantitative studies have indicated that patients with liver transplant achieved better QOL 10-30 years after liver transplantation than pre-surgery, yet the enhanced QOL for recipients does not always return to normal after transplantation (Desai et al., 2008; Duffy et al., 2010). This research provides further novel insights through phenomenological understanding of post-transplant recipients' experiences to examine the emergence of factors that, if understood and sensitively addressed, can lead to a realistic look at 
the journey across the transplantation trajectory and life-long recovery. Successful transition from hospital to home and moving beyond the initial recovery phase is not only dependent on family support but also depends on community services. Moving beyond recovery requires resumption of valued roles, reconceptualisation of health and wellbeing, re-transformation of a sense of self, and redefining the notion of normalcy. Re-establishing roles and responsibilities play a significant part in the journey towards reclaiming QOL post-transplantation. It is clear that QOL after transplantation encompasses much more than immunosuppressive treatment and physical functioning. Liver transplant recipients, as do other marginalised groups in our communities, need access to advocates such as social workers or health/patient navigators to ensure they are receiving support to which they are legally entitled. The social work profession has important contributions to make in the field of organ transplantation. Its role in emergency medicine, chronic illness management and working with trauma patients and their families has been highly recognised (Bright, Craven, \& Kelly, 1990; Carosella, 1984; Dhooper \& Wilson, 1989). The social work professional can provide a holistic perspective in medical care by putting the illness experience of individuals in the wider context of emotional, social, familial, economic and cultural landscapes, rather than a one-size-fits-all solution.

\section{Acknowledgements}

We thank and acknowledge the transplant recipients who contributed to the research. Dr Bethli Wainwright, a liver transplant recipient, died on December 25, 2010. Her supervisors (Professors Waring

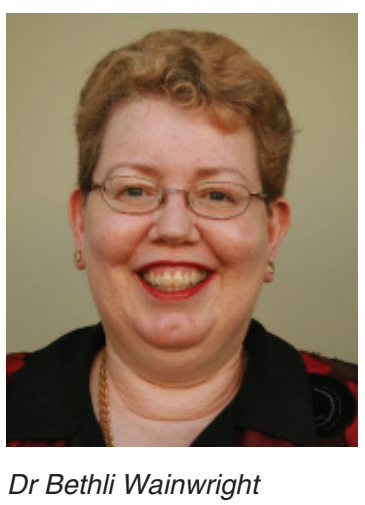

and Gane) had given an undertaking that her work would be completed and subsequently, she graduated posthumously with her PhD. in 2011. Jülich, Waring, Yeung, and Green continue to work on her behalf to share her findings. The difficulties of writing up the research of others and maintaining their integrity are evident in that it is now seven years since thesis completion. Finally, we thank the peer reviewers whose suggestions have helped us do Bethli proud.

\section{References}

Åberg, F., Isoniemi, H., \& Höckerstedt, K. (2011). Long-term results of liver transplantation. Scandinavian Journal of Surgery, 100(1), 14-21. doi:10.1177/145749691110000104

Akazawa, C., Nishizono, T., Yamamoto, M., Teraguchi, S., \& Hayashi, Y. (2013). Investigation of actual daily lifestyle leading to continuous self-management after living-donor liver transplantation: More than 5 years living with livingdonor liver transplantation and emotions of recipients. Japan Journal of Nursing Science, 10(1), 79-88. doi:10.1111/j.1742-7924.2012.00214.x

Blanch, J., Sureda, B., Flaviá, M., Marcos, V., de Pablo, J., De Lazzari, E., . . Visa, J. (2004). Psychosocial adjustment to orthotopic liver transplantation in 266 recipients. Liver Transplantation, 10(2), 228-234. doi:10.1002/lt.20076

Boaz, A., \& Morgan, M. (2014). Working to establish "normality" post-transplant: A qualitative study of kidney transplant patients. Chronic IIIn, 10(4), 247-258. doi:10.1177/1742395313504789

Bright, M. J., Craven, J. L., \& Kelly, P. J. (1990). Assessment and management of psychosocial stress in lung transplant candidates. Toronto Lung Transplant Group. Health Social Work, 15(2), 125-132.

Carosella, J. (1984). Picking up the pieces: The unsuccessful kidney transplant. Health \& Social Work, 9(2), 142-152. doi:10.1093/hsw/9.2.142

Casey, R. P. (1996). Fighting for life: The story of a courageous pro-life democrat whose own brush with death made medical history. Dallas, TX: Word Publishing.

De Vito Dabbs, A., Hoffman, L. A., lacono, A. T., Zullo, T. G., McCurry, K. R., \& Dauber, J. H. (2004). Are symptom reports useful for differentiating between acute rejection and pulmonary infection after lung transplantation? Heart Lung, 33(6), 372-380.

Denzin, N. K. (1978). The research act: $A$ theoretical introduction to sociological methods (2nd ed.). New York, NY: McGraw-Hill.

Desai, R., Jamieson, N. V., Gimson, A. E., Watson, C. J., Gibbs, P., Bradley, J. A., \& Praseedom, R. K. (2008). Quality of life up to 30 years following liver transplantation. Liver Transplant, 14(10), 1473-1479. doi:10.1002/lt.21561

Dew, M. A., Goycoolea, J. M., Switzer, G. E., \& Allen, A. S. (2000). Quality of life in organ transplantation: Effects on adult recipients and their families. In P. D. A. Trzepacz 
\& A. DiMartini (Eds.), The transplant patient: Biological, psychiatric and ethical issues in organ transplantation (pp. 67-145). Cambridge, UK: Cambridge University Press.

Dew, M. A., Switzer, G. E., Goycoolea, J. M., Allen, A. S., DiMartini, A., Kormos, R. L., \& Griffith, B. P. (1997). Does transplantation produce quality of life benefits? A quantitative analysis of the literature. Transplantation, 64(9), 1261-1273.

Dhooper, S. S., \& Wilson, C. P. (1989). Social work and organ tTransplantation. Health \& Social Work, 14(2), 115-121. doi:10.1093/hsw/14.2.115

Doering, L. V., Chen, B., Deng, M., Mancini, D., Kobashigawa, J., \& Hickey, K. (2017). Perceived contro and health-related quality of life in heart transplant recipients. European Journal of Cardiovascular Nursing.. doi:10.1177/1474515117749225

Dudley, T., Chaplin, D., Clifford, C., \& Mutimer, D. J. (2007). Quality of life after liver transplantation for hepatitis C infection. Quality of Life Research, 16(8), 1299-1308. doi:10.1007/s11136-007-9244-y

Duffy, J. P., Kao, K., Ko, C. Y., Farmer, D. G., McDiarmid, S. V., Hong, J. C., . . Busuttil, R. W. (2010). Longterm patient outcome and quality of life after liver transplantation: Analysis of 20-year survivors. Annals of Surgery, 252(4), 652-661. doi:10.1097/ SLA.0b013e3181f5f23a

Fagerlind, H., Ring, L., Brulde, B., Feltelius, N., \& Lindblad, A. K. (2010). Patients' understanding of the concepts of health and quality of life. Patient Education and Counseling, 78(1), 104-110. doi:10.1016/j. pec.2009.05.016

Flynn, K., Daiches, A., Malpus, Z., Yonan, N., \& Sanchez, M. (2013). "A post-transplant person": Narratives of heart or lung transplantation and intensive care unit delirium. Health, 18(4), 352-368. doi:10.1177/1363459313501356

Forsberg, A., Bäckman, L., \& Möller, A. (2000). Experiencing liver transplantation: A phenomenological approach. Journal of Advanced Nursing, 32(2), 327-334. doi:10.1046/j.1365-2648.2000.01480.x

Forsberg, A., Cavallini, J., Fridh, I., \& Lennerling, A. (2016). The core of social function after solid organ transplantation. Scandinavian Journal of Caring Sciences, 30(3), 458-465. doi:10.1111/scs.12264

Gane, E., McCall, J., Streat, S., Gunn, K., Yeong, M. L., Fitt, S., ... Munn, S. (2002). Liver transplantation in New Zealand: The first four years. New Zealand Medical Journal, 115(1159), 1-13.

Graarup, J., Mogensen, E. L., Missel, M., \& Berg, S. K. (2017). Life after a lung transplant: A balance of joy and challenges. Journal of Clinical Nursing, 26(21-22), 3543-3552. doi:10.1111/jocn. 13724

Grady, K. L., Wang, E., White-Williams, C., Naftel, D. C., Myers S., Kirklin, J. K., . . . Heroux, A. (2013). Factors associated with stress and coping at 5 and 10 years after heart transplantation. Journal of Heart Lung Transplantation, 32(4), 437-446. doi:10.1016/j.healun.2012.12.012

Hagman, L., \& Gold, T. (2001). Hello darlin': Tall (and absolutely true) tales about my life. New York, NY: Simon \& Schuster.

Hill, S., Harries, U., \& Popay, J. (1993). The SF 36 health survey questionnaire. Unanswered questions remain. British Medical Journal (Clinical Research Ed.). doi:10.1136/bmj.307.6901.449-a
Hunt, M. R. (2009). Strengths and challenges in the use of interpretive description: Reflections arising from a study of the moral experience of health professionals in humanitarian work. Qualitative Health Research, 19(9), 1284-1292. doi:10.1177/1049732309344612

Ivarsson, B., Ekmehag, B., \& Sjöberg, T. (2012). Patients' experiences of information and support during the first six months after heart or lung transplantation. European Journal of Cardiovascular Nursing, 12(4), 400-406. doi:10.1177/1474515112466155

Ko, D., Lee, I., \& Muehrer, R. J. (2016). Informational needs of liver transplant recipients during a two-year posttransplant period. Chronic IIIness, 12(1), 29-40. doi:10.1177/1742395315601415

Littlefield, C., Abbey, S., Fiducia, D., Cardella, C., Greig, P., Levy, G., . . . Winton, T. (1996). Quality of life following transplantation of the heart, liver, and lungs. General Hospital Psychiatry, 18(Supplement 6), 36-47. doi:10.1016/S0163-8343(96)00082-5

Lumby, J. (1997). Liver transplantation: The death/life paradox. International Journal of Nursing Practice, 3(4), 231-238. doi:10.1111/j.1440-172X.1997.tb00107.x

Maier, F., \& Maier, G. (1991). Sweet reprieve: One couple's journey to the frontiers of medicine. New York, NY: Crown Publishers.

Mantulak, A., \& Nicholas, D. B. (2016). "We're not going to say it's suffering; we're going to say it's an experience": The lived experience of maternal caregivers in pediatric kidney transplantation. Social Work Health Care, 55(8), 580-594. doi:10.1080/00981389.2016.1208712

Martin, S. C., Stone, A. M., Scott, A. M., \& Brashers, D. E. (2009). Medical, personal, and social forms of uncertainty across the transplantation trajectory. Qualitative Health Research, 20(2), 182-196. doi:10.1177/1049732309356284

McKenna, K., Liddle, J., Brown, A., Lee, K., \& Gustafsson, L. (2009). Comparison of time use, role participation and life satisfaction of older people after stroke with a sample without stroke. Australian Occupational Therapy Journal, 56(3), 177-188. doi:10.1111/j.1440-1630.2007.00728.x

Molassiotis, A., Van Den Akker, O. B. A., \& Boughton, B. J. (1997). Perceived social support, family environment and psychosocial recovery in bone marrow transplant long-term survivors. Social Science \& Medicine, 44(3), 317-325. doi:10.1016/S0277-9536(96)00101-3

Monroe, J., \& Raiz, L. (2005). Barriers to employment following renal transplantation: Implications for the social work professional. Social Work Health Care, 40(4), 61-81. doi:10.1300/J010v40n04 04

Neukom, M., Corti, V., Boothe, B., Boehler, A., \& Goetzmann, L. (2012). Fantasized recipient-donor relationships following lung transplantations: A qualitative case analysis based on patient narratives. The International Journal of Psychoanalysis, 93(1), 117-137. doi:10.1111/j.17458315.2011.00496.x

Oakley, F., Kielhofner, G., Barris, R., \& Reichler, R. K. (1986). The role checklist: Development and empirical assessment of reliability. OTJR: Occupation, Participation and Health, 6(3), 157-170. doi:10.1177/153944928600600303

Paris, W., Calhoun-Wilson, G., Slentz, B., Dahr, A. S., Tebow, S., Hart, J., \& Harrison, J. (1997). Employment and the transplant patient. Journal of Rehabilitation, 63(2), 10-14. 
Robertson, G. (1999). Individuals' perception of their quality of life following a liver transplant: An exploratory study. Journal of Advanced Nursing, 30(2), 497-505. doi:10.1046/j.1365-2648.1999.01105.x

Rosenberger, E. M., Dew, M. A., DiMartini, A. F., DeVito Dabbs, A. J., \& Yusen, R. D. (2012). Psychosocial issues facing lung transplant candidates, recipients and family caregivers. Thoracic Surgery Clinics, 22(4), 517-529. doi:10.1016/j.thorsurg.2012.08.001

Ryu, J. H., Kim, M. H., \& Kang, I. S. (2003). A study on the compliance and educational demand of renal transplantation patient. The Korean Journal of Rehabilitation Nursing, 6(2), 226-238.

Sanderson, T., Calnan, M., Morris, M., Richards, P., \& Hewlett, S. (2011). Shifting normalities: Interactions of changing conceptions of a normal life and the normalisation of symptoms in rheumatoid arthritis. Sociology of Health \& IIIness, 33(4), 618-633. doi:10.1111/j.1467-9566.2010.01305.x

Sargent, S., \& Wainwright, S. P. (2007). A qualitative study exploring patients received quality of life following an emergency liver transplant for acute liver failure. Intensive and Critical Care Nursing, 23(5), 272-280. doi:10.1016/j.iccn.2007.03.005

Schipper, K., Abma, T. A., Koops, C., Bakker, I., Sanderman, R., \& Schroevers, M. J. (2014). Sweet and sour after renal transplantation: A qualitative study about the positive and negative consequences of renal transplantation. British Journal of Health Psychology, 19(3), 580-591. doi:10.1111/bjhp.12057

Scott, P. J. (2010). Participation in valued roles postliver transplant. The British Journal of Occupational Therapy, 73(11), 517-523. doi:10.4276/03080221 0X12892992239198

Scott, P. J., \& Brown, V. L. (2012). Resumption of valued activities in the first year post liver transplant. Occupational Therapy in Health Care, 26(1), 48-63. doi:10.3109/07380577.2011.643856

Seiler, A., Klaghofer, R., Ture, M., Komossa, K., MartinSoelch, C., \& Jenewein, J. (2016). A systematic review of health-related quality of life and psychological outcomes after lung transplantation. The Journal of Heart and Lung Transplantation, 35(2), 195-202. doi:10.1016/j.healun.2015.07.003

Siminoff, L. A., \& Chillag, K. (1999). The fallacy of the "gift of life." Hastings Center Report, 29(6), 34-41. doi: $10.2307 / 3527870$

Simmons, R. G., \& Abress, L. (1990). Quality-of-life issues for end-stage renal disease patients. American Journal of Kidney Diseases, 15(3), 201-208. doi:10.1016/S02726386(12)80763-3

Thorne, S. (2008). Interpretive description. Walnut Creek, CA: Left Coast Press.

Thorne, S., Kirkham, S. R., \& MacDonald-Emes, J. (1997). Interpretive description: A noncategorical qualitative alternative for developing nursing knowledge. Research in Nursing \& Health, 20(2), 169-177.

Thurmond, V. A. (2001). The point of triangulation. Journal of Nursing Scholarship, 33(3), 253-258. doi:10.1111/j.15475069.2001.00253.x

Tong, A., Chapman, J. R., Israni, A., Gordon, E. J., \& Craig, J. C. (2013). Qualitative research in organ transplantation: Recent contributions to clinical care and policy. American Journal of Transplantation, 13(6), 1390-1399. doi:10.1111/ajt.12239

van der Mei, S. F., van Son, W. J., van Sonderen, E. L. P., de Jong, P. E., Groothoff, J., \& van den Heuvel, W. J. A. (2007). Factors determining social participation in the first year after kidney transplantation: A prospective study. Transplantation, 84(6), 729-737. doi:10.1097/01. tp.0000281409.35702.53

Wainwright, B. (2011a). The lived experience of liver transplant recipients in New Zealand. (doctoral dissertation). Auckland University of Technology, Auckland, New Zealand. Retrieved from http://aut. researchgateway.ac.nz/handle/10292/2536

Wainwright, B. (2011b). Liver transplant recipients' reflections on organ donors and organ donation: A preliminary analysis. Sites, 8(1), 83-107. doi:10.11157/sitesvol8iss 1 id146

Wainwright, B., Jülich, S., Waring, M., Yeung, P., \& Green, J. K. (2016). Leaving the experts: Experiences of liver transplantation recipients in New Zealand. Nursing Praxis in New Zealand, 32(3), 7-19.

Walker, A., \& Lowenstein, A. (2009). European perspectives on quality of life in old age. European Journal of Ageing, 6(2), 61-66. doi:10.1007/s10433-009-0117-9

Xu, J., Adeboyejo, O., Wagley, E., Aubrecht, J., Song, M. K., Thiry, L., \& Dabbs, A. D. (2012). Daily burdens of recipients and family caregivers after lung transplant. Progress in Transplantation, 22(1), 41-47.

Zare, N. V., Mohammadi, E., Zarea, K., Ehahi, N., \& Manzari, Z. (2015). The realities of living with a transplanted kidney: A qualitative study. Jundishapur Journal of Chronic Disease Care, 4(3), e28043. doi:10.5812/jjcdc.28043v2

Zilberfein, F., Hutson, C., Snyder, S., \& Epstein, I. (2002). Social work practice with pre- and post-liver transplant patients. Social Work in Health Care, 33(3-4), 91-104. doi:10.1300/J010v33n03_07 